\title{
Perforation and post-polypectomy bleeding complicating colonoscopy in a population-based screening program
}

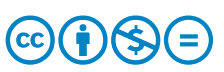

\author{
Authors \\ Institutions \\ 1 University of Toronto, Toronto, Ontario, Canada \\ 2 Institute for Clinical Evaluative Sciences - Cancer \\ Program, Toronto, Ontario, Canada
}

Lawrence F. Paszat ${ }^{1}$, Rinku Sutradhar ${ }^{1}$, Jin Luo ${ }^{2}$, Linda Rabeneck ${ }^{1}$, Jill Tinmouth ${ }^{1}$

submitted 22.7.2020

accepted after revision 23.11 .2020

Bibliography

Endosc Int Open 2021; 9: E637-E645

DOI 10.1055/a-1381-7149

ISSN 2364-3722

(c) 2021. The Author(s).

This is an open access article published by Thieme under the terms of the Creative Commons Attribution-NonDerivative-NonCommercial License, permitting copying and reproduction so long as the original work is given appropriate credit. Contents may not be used for commercial purposes, or adapted, remixed, transformed or built upon. (https://creativecommons.org/licenses/by-nc-nd/4.0/)

Georg Thieme Verlag KG, Rüdigerstraße 14,

70469 Stuttgart, Germany

Corresponding author

Lawrence Paszat, BA, MD, MS, FRCPC, University of Toronto, Sunnybrook Health Sciences Centre, T2-156 2075 Bayview

Avenue, Toronto, Ontario M4N3M5, Canada

Fax: + 014164806002

lawrence.paszat@sunnybrook.ca

\section{ABSTRACT}

Background and study aims We aimed to estimate the rate of hospital admissions for perforation and for post-polypectomy bleeding, after outpatient colonoscopy following a first positive fecal occult blood test screen through the population-based ColonCancerCheck program in Ontario, Canada.

Patients and methods We identified all individuals aged 50 to 74 years with a first positive CCC gFOBT screening result from 2008 to 2017 who underwent outpatient colonoscopy $\leq 6$ months later and who did not receive a diagnosis of $C R C \leq 24$ months later. We identified inpatient hospital admissions for colonic perforation $\leq 7$ days after and for postpolypectomy bleeding $\leq 14$ days following colonoscopy.

Results Among 121,626 individuals who underwent colonoscopy, the rate of perforation was 0.6 per 1000 from 2008 to 2012 and 0.4 per 1000 from 2013 to 2017. The rate was elevated among those aged 70 to 74 years; those with comorbidities; when colonoscopy was performed by endoscopists other than gastroenterologists or endoscopists with low prior year volume; and when polypectomy was performed during colonoscopy. The rate of bleeding was 4.3 per 1000 and was elevated among those aged 70 to 74 years, those with comorbidity, and with complex polypectomy. Both outcomes were more common among those aged 70 to 74 years, those with a 5 -year cumulative Charlson score $\geq 1$, those with prior hospitalization for ischemic heart disease, and those with endoscopists whose prior year colonoscopy volume was in the three lower quartiles.

Conclusions Colonic perforation and post-polypectomy bleeding, among participants of population-based colorectal screening programs who test positive in the absence of colorectal cancer, are infrequent but serious complications, which increase with participant age and comorbidity, and with endoscopist characteristics.

\section{Introduction}

After publication of a meta-analysis of four randomized trials of colorectal screening by guaiac fecal occult blood testing (gFOBT) showing reduction in colorectal cancer (CRC) mortality [1] and two Canadian guidelines recommending its adoption $[2,3]$, the Ontario Ministry of Health and Long Term Care funded a population-based colorectal screening program, oper- ated by Cancer Care Ontario as ColonCancerCheck (CCC). Since 2008, CCC has recommended biennial screening by gFOBT for asymptomatic individuals between 50 and 74 years of age who do not have a first degree relative affected by CRC. CCC processes and performance indicators have been previously published $[4,5]$.

Individuals with a positive gFOBT result are recommended to proceed to diagnostic colonoscopy. Colonoscopy for any indica- 
tion is associated with complications, including perforation and bleeding. In the context of a population-based colorectal screening program using stool testing, most asymptomatic individuals who undergo colonoscopy for a positive gFOBT screening result, and who experience perforation and/or bleeding, will not have CRC.

In this paper, we aimed to determine the rate of hospital admission for colonoscopic perforation $\leq 7$ days following the date of outpatient colonoscopy, and the frequency of hospital admission for bleeding due to colonoscopic polypectomy $\leq 14$ days following the colonoscopy, among CCC participants.

The measurement of these rates is important for estimating the magnitude of unintended harms of population-based colorectal screening programs, and how these rates vary according to the baseline participant and endoscopist covariates, so that colonoscopy quality improvement efforts may be refined and intensified.

\section{Methods}

The objective of this work was to determine the frequency of perforation and post-polypectomy bleeding related to the first outpatient colonoscopy following a first positive gFOBT in the provincial colorectal screening program, ColonCancerCheck (CCC), who did not receive a diagnosis of CRC $\leq 24$ months following colonoscopy.

Using an encryption of each person's Ontario Health Insurance number, we linked the first positive gFOBT report per patient in the CCC database of gFOBT results from 2008 to 2017 , to the Registered Individuals Database (RPDB) of the Ontario Health Insurance Plan (OHIP). We excluded individuals whose age was outside the range of ages 50 to 74 years, those without an Ontario address, and those with a prior history of inflammatory bowel disease (via linkage to the Ontario Crohn's and Colitis Database), total colectomy (via linkage to the OHIP billing claims file) or colorectal cancer (by linkage to the Ontario Cancer Registry [OCR]). We excluded individuals without an outpatient colonoscopy $\leq 6$ months following the date of the first positive gFOBT, and individuals with a diagnosis of colorectal cancer in the OCR within 24 months after the date of the colonoscopy.

To characterize the study population on the index date beyond age and sex, we computed the Charlson comorbidity score for the 5 years prior to the date of the first positive gFOBT using the algorithm adapted by ICES from the Deyo adaptation of the Charlson score for its computation from health services data bases, based on the Canadian version of ICD10 diagnosis codes [6], as contained in the Canadian Institute for Health Information's (CIHI) Discharge Abstract Database (DAD), expressed as 0 versus 1 or higher. We computed the Resource Utilization Band (RUB) for the 2 years prior. The RUB is a categorization of morbidity and of utilization of health services, for which we applied the Ambulatory Care Group program (www.acg) to the following health services administrative databases for each person: CIHI DAD, Same Day Surgery Database (SDS) and the National Ambulatory Care Record System Database (NACRS) plus the OHIP billing claims files [7]. We combined RUB bands
0 to 3, representing non-users, health users, users with low morbidity, and users with moderate morbidity, and we combined bands 4 and 5 , representing users with high and very high levels of morbidity. As in our previous work [5, 8, 9], we assigned ecologic-level socioeconomic status linking residence codes to self-reported census data, we identified diabetes mellitus, chronic obstructive pulmonary disease, and hospitalization for ischemic heart disease using validated algorithms, and from OHIP physician billing claims we identified the specialty of the endoscopist, the endoscopist's prior year colonoscopy volume, colonoscopy completeness, and anesthesia attendance at colonoscopy.

The methods to ascertain inpatient hospitalization for perforation and for post-polypectomy bleeding from health services administrative databases that are constructed and assembled for other purposes build on the developmental work we have previously published $[8,9]$.

To identify potential cases of colonoscopic perforation among all those who had a colonoscopy $\leq 6$ months following the date of the first positive gFOBT, we searched for records of inpatient admission within 7 days after the colonoscopy (because of our prior work showing all validated cases of perforation were admitted within five days following colonoscopy [9]) in the CIHI DAD containing International Classification of Diseases version 10 (ICD10) diagnosis codes for accidental puncture and laceration during a procedure, perforation of intestine (non-traumatic), acute peritonitis, other or nonspecific peritonitis, laceration of colon without open wound, or injury not otherwise specified of intra-abdominal organ. We excluded records containing diagnostic codes for injury or neoplasm, or control of bleeding or excision of the spleen or of organs of the digestive tract proximal to the colon.

To identify cases of post-polypectomy bleeding, we identified the subcohort of those individuals whose colonoscopy was accompanied by $\geq 1$ OHIP billing claims for complex polypectomy (E685 total excision of very large sessile polyp $>3 \mathrm{~cm}$ through colonoscope) or standard polypectomy (Z571 excision of first polyp $\geq 3 \mathrm{~mm}$ through colonoscope) on the date of the colonoscopy. Among these, we searched for records of inpatient admission within 14 days following colonoscopic polypectomy (based on our prior work showing that $96 \%$ of validated cases of post-colonoscopy bleeding were admitted within 14 days [9] ) with any ICD10 diagnosis codes for hemorrhage and hematoma complicating a procedure, hemorrhage of anus and rectum, posthemorrhagic anemia, melena, gastrointestinal hemorrhage, unintentional cut, puncture, perforation, or hemorrhage during surgical and medical care, during endoscopic examination or other surgical and medical care. We excluded records containing diagnostic codes for injury, or neoplasm, or $\mathrm{CCl}$ codes for control of bleeding or excision of the spleen or of organs of the digestive tract proximal to the colon.

We explored the distributions of baseline characteristics among individuals stratified by outcome, using frequencies and percentages. For each outcome, we described individuals with and without the outcome, by baseline covariates and colonoscopy descriptors. With large population-based cohorts, mean standardized differences are preferred over $P$ values to 
assess imbalance in covariate distributions $[10,11]$; an absolute value higher than 0.1 implies a meaningful difference in the covariate distribution between those experiencing the outcome compared to those who did not. Outcome rates per 1,000 were also calculated for each characteristic.

\section{Results}

Among 170,670 individuals without a history of colorectal cancer who received a positive gFOBT result between 2008 and $2017,127,872$ (74.9\%) underwent colonoscopy $\leq 6$ months following the date of the positive test. Of them, 121,626 (95.1\%) did not receive a diagnosis of colorectal cancer within 24 months of the positive test, and constitute the study population for these analyses.

The majority of this cohort were aged between ages 50 and 64 years $(82,875 / 121,626,68.1 \%)$ on the date of the positive gFOBT and were male $(65,214 / 121,626,53.6 \%)$. During the 24 months prior to the date of positive gFOBT, 29,237/92,389 fell into Resource Utilization Bands 4 and 5, and the 5-year cumulative Charlson score was $\geq 1$ among 16,329 of 121,626 (13.4\%). Diabetes mellitus was present among 27,958 of 121,626 (23.0 $\%)$, chronic obstructive pulmonary disease among 17,387 of $121,626(14.3 \%)$ and 3,627 of 117,999 (3.0\%) had a prior hospitalization for ischemic heart disease ( $\triangleright$ Table 1 ).

The endoscopist was a general surgeon for 66,825 of 121,626 (54.9\%) of the patients, and was in the highest quartile of prior year colonoscopy volume for 64,969 patients (53.4\%). Colonoscopy was complete to cecum or terminal ileum for 118,090 of 121,626 (97.1\%) of patients. An anesthesiologist was in attendance at 63,314 of 121,626 (52.1\%) colonoscopies. One or more polypectomies were performed among $51,310$ of $121,626(42.2 \%)$ ( $\triangleright$ Table 1$)$.

- Table 1 Cohort with colonoscopy $\leq 6$ months after positive gFOBT.

\begin{tabular}{|l|l|}
\hline \multicolumn{1}{|l|}{ Total } & 121,626 \\
\hline Year of positive gFOBT & \\
\hline - $2008-2012$ & $52,425(43.1 \%)$ \\
\hline - $2013-2017$ & $69,201(56.9 \%)$ \\
\hline Age on date of positive gFOBT & \\
\hline - $50-64$ & $82,875(68.1 \%)$ \\
\hline - $65-69$ & $22,026(18.1 \%)$ \\
\hline - $70-74$ & $16,725(13.8 \%)$ \\
\hline Sex & \\
\hline - Female & $56,412(46.4 \%)$ \\
\hline - Male & $65,214(53.6 \%)$ \\
\hline Socioeconomic status & $14,909(12.3 \%)$ \\
\hline - Rural or missing & $66,143(54.4 \%)$ \\
\hline - Urban median household income quintiles & \\
\hline & $1-3$
\end{tabular}

- Table 1 (Continuation)

\begin{tabular}{|l|l|}
\hline Total & 121,626 \\
\hline $\begin{array}{l}\text { Urban median household income quintiles } \\
4-5\end{array}$ & $40,574(33.3 \%)$ \\
\hline ACG Resource Utilization Band & \\
\hline " $0-3$ & $92,389(76.0 \%)$ \\
\hline " $4-5$ & $29,237(24.0 \%)$ \\
\hline Deyo modification of Charlson score & \\
\hline " 0 & $105,297(86.6 \%)$ \\
\hline " $\geq 1$ & $16,329(13.4 \%)$ \\
\hline Diabetes mellitus & \\
\hline " Yes & $27,958(23.0 \%)$ \\
\hline " No & $93,668(77.0 \%)$ \\
\hline Chronic obstructive pulmonary disease & \\
\hline - Yes & $17,387(14.3 \%)$ \\
\hline - No & $104,239(85.7 \%)$ \\
\hline
\end{tabular}

Ischemic heart disease hospitalization

- Yes

$3,627(3.0 \%)$

- No $117,999(97.0 \%)$

Number of patients categorized by endoscopist specialty

- Gastroenterology $36,651(30.1 \%)$

- General Surgery $66,825(54.9 \%)$

- Internal Medicine or other $18,150(15.0 \%)$

Number of patients categorized by endoscopist's prior year colonoscopy volume

\begin{tabular}{|c|c|}
\hline $\begin{array}{l}\text { - 0-202 colonoscopies (lowest quartile of } \\
\text { prior year volume) }\end{array}$ & $4,896(4.0 \%)$ \\
\hline $\begin{array}{l}\text { 203-680 colonoscopies (interquartile } \\
\text { range) }\end{array}$ & $51,761(42.6 \%)$ \\
\hline $\begin{array}{l}\text { - } \geq 681 \text { colonoscopies (highest quartile of } \\
\text { prior year volume) }\end{array}$ & $64,969(53.4 \%)$ \\
\hline \multicolumn{2}{|l|}{$\geq 1$ polypectomy performed at colonoscopy } \\
\hline - Yes & $51,310(42.2 \%)$ \\
\hline - No & $70,316(57.8 \%)$ \\
\hline \multicolumn{2}{|l|}{ Colonoscopy completeness } \\
\hline - Complete & $118,090(97.1 \%)$ \\
\hline - Incomplete & $3,536(2.9 \%)$ \\
\hline \multicolumn{2}{|l|}{ Anesthesia attendance at colonoscopy } \\
\hline - Yes & $63,314(52.1 \%)$ \\
\hline - No & $58,312(47.9 \%)$ \\
\hline $\begin{array}{l}\text { SD, standard deviation; gFOBT, guiac fecal occult } \\
\text { ACG, ambulatory care group. }\end{array}$ & testing; \\
\hline
\end{tabular}


Overall, 57 of 121,626 patients $(0.0047 \%)$ were admitted to hospital with perforation $\leq 7$ days following colonoscopy for a positive gFOBT: the rate of admission for perforation was 0.5 per thousand ( $\triangleright$ Table 2 ). The rate of perforation fell from 0.6 per 1,000 between 2008 and 2012 to 0.4 per thousand between 2013 and 2017; the standardized difference of the proportions was 0.23 , indicating a meaningful difference. The rate of perforation was markedly increased among those at ages 70 to 74 (1.1 per 1,000 individuals). Comparing the proportion of age 70 to 74 individuals among those with a perforation versus those without perforation indicates a large standardized difference of 0.44 . The rate of perforation was markedly elevated among those with a prior 5-year cumulative Charlson score $\geq 1$, those with chronic obstructive lung disease, and those with

Table 2 Admission for perforation $\leq 7$ days following colonoscopy.

\begin{tabular}{|c|c|c|c|c|}
\hline & Perforation & No perforation & SD & Rate per 1000 \\
\hline Overall & 57 & 121,569 & $\mathrm{n} / \mathrm{a}$ & 0.5 \\
\hline \multicolumn{5}{|l|}{ Year of false-positive gFOBT } \\
\hline - 2008-2012 & $31(54.4 \%)$ & $52,394(43.1 \%)$ & 0.23 & 0.6 \\
\hline . 2013-2017 & $26(45.6 \%)$ & $69,175(56.9 \%)$ & 0.23 & 0.4 \\
\hline \multicolumn{5}{|l|}{ Age on date of false-positive gFOBT } \\
\hline - 50-64 & $28(49.1 \%)$ & $82,847(68.1 \%)$ & 0.39 & 0.3 \\
\hline - 65-69 & $11(19.3 \%)$ & $22,105(18.1 \%)$ & 0.03 & 0.5 \\
\hline . $70-74$ & $18(31.6 \%)$ & $16,707(13.7 \%)$ & 0.44 & 1.1 \\
\hline \multicolumn{5}{|l|}{ Sex } \\
\hline - Female & $29(50.9 \%)$ & $56,383(46.4 \%)$ & 0.09 & 0.5 \\
\hline - Male & $28(49.1 \%)$ & $65,186(53.6 \%)$ & 0.09 & 0.4 \\
\hline \multicolumn{5}{|l|}{ Socioeconomic status } \\
\hline - Rural or missing & $10(17.5 \%)$ & $14,899(12.3 \%)$ & 0.15 & 0.7 \\
\hline - Urban median household income quintiles 1-3 & $31(54.4 \%)$ & $66,112(54.4 \%)$ & 0 & 0.5 \\
\hline - Urban median household income quintiles 4-5 & $16(28.1 \%)$ & $40,558(33.4 \%)$ & 0.11 & 0.4 \\
\hline \multicolumn{5}{|l|}{ ACG Resource Utilization Band } \\
\hline - $0-3$ & $41(71.9 \%)$ & $92,348(76.0 \%)$ & 0.09 & 0.4 \\
\hline - $4-5$ & $16(28.1 \%)$ & $29,221(24.0 \%)$ & 0.09 & 0.5 \\
\hline \multicolumn{5}{|l|}{ Deyo modification of Charlson score } \\
\hline .0 & $41(71.9 \%)$ & $105,256(86.6 \%)$ & 0.37 & 0.4 \\
\hline - $\geq 1$ & $16(28.1 \%)$ & $16,313(13.4 \%)$ & 0.37 & 1.0 \\
\hline \multicolumn{5}{|l|}{ Diabetes mellitus } \\
\hline - Yes & $14(24.6 \%)$ & $27,944(23.0 \%)$ & 0.04 & 0.5 \\
\hline - No & $43(75.4 \%)$ & $93,625(77.0 \%)$ & 0.04 & 0.5 \\
\hline \multicolumn{5}{|l|}{ Chronic obstructive pulmonary disease } \\
\hline - Yes & $14(24.6 \%)$ & $17,373(14.3 \%)$ & 0.26 & 0.8 \\
\hline - No & $43(75.4 \%)$ & $104,196(85.7 \%)$ & 0.26 & 0.4 \\
\hline \multicolumn{5}{|l|}{ Ischemic heart disease hospitalization } \\
\hline - Yes & $6(10.5 \%)$ & $3,621(3.0 \%)$ & 0.3 & 1.7 \\
\hline - No & $51(89.5 \%)$ & $117,948(97.0 \%)$ & 0.3 & 0.4 \\
\hline \multicolumn{5}{|c|}{ Number of patients categorized by endoscopist's specialty } \\
\hline - Gastroenterology & $10(17.5 \%)$ & $36,641(30.1 \%)$ & 0.3 & 0.3 \\
\hline - General Surgery & $37(64.9 \%)$ & $66,788(54.9 \%)$ & 0.2 & 0.6 \\
\hline - Internal Medicine or other & $10(17.5 \%)$ & $18,140(14.9 \%)$ & 0.07 & 0.6 \\
\hline
\end{tabular}


- Table 2 (Continuation)

\begin{tabular}{|c|c|c|c|c|}
\hline & Perforation & No perforation & SD & Rate per 1000 \\
\hline \multicolumn{5}{|c|}{ Number of patients categorized by endoscopist's prior year colonoscopy volume } \\
\hline - 0-202 colonoscopies (lowest quartile of prior year volume) & $6(10.5 \%)$ & $4,890(4.0 \%)$ & 0.25 & 1.2 \\
\hline - 203-680 colonoscopies (interquartile range) & $31(54.4 \%)$ & $51,730(42.6 \%)$ & 0.24 & 0.6 \\
\hline - $\geq 681$ colonoscopies (highest quartile of prior year volume) & $20(35.1 \%)$ & $64,949(53.4 \%)$ & 0.38 & 0.3 \\
\hline \multicolumn{5}{|l|}{$\geq 1$ polypectomy performed at colonoscopy } \\
\hline - Yes & $38(66.7 \%)$ & $51,272(42.2 \%)$ & 0.51 & 0.7 \\
\hline - No & $19(33.3 \%)$ & $70,297(57.8 \%)$ & 0.51 & 0.3 \\
\hline \multicolumn{5}{|l|}{ Anesthesia attendance } \\
\hline - Yes & $32(56.1 \%)$ & $63,282(52.1 \%)$ & 0.08 & 0.5 \\
\hline . No & $25(43.9 \%)$ & $58,287(47.9 \%)$ & 0.08 & 0.4 \\
\hline
\end{tabular}

prior ischemic heart disease hospitalization. The differences in distribution of these three baseline covariates are significantly different between those with and without perforation, with standardized differences of $0.37,0.26$, and 0.30 respectively. The rate of perforation was similar between females and males, among patients at various levels of the Resource Utilization Bands, and among patients with or without diabetes.

The distributions of some baseline endoscopist and colonoscopic covariates were importantly different, for example, the distribution of gastroenterologists and general surgeons as endoscopists (standardized differences 0.3 and 0.2 respectively). Patients whose colonoscopy was performed by a gastroenterologist had a lower rate of perforation, 0.3 per thousand, as did those whose endoscopists prior year colonoscopy volume was in the highest quartile of prior year colonoscopy volume. In addition, the distribution of the performance of $\geq 1$ polypectomy or no polypectomy was importantly different (standardized differences both 0.51). Among those patients who underwent polypectomy the rate of perforation was 0.7 per 1,000 .

The distribution of baseline covariates and procedural factors between those who were and were not admitted for post polypectomy bleeding are shown with standardized differences, most of which were importantly different, with the exception of the year of the gFOBT, the presence or absence of Chronic Obstructive Pulmonary Disease, the specialty of the endoscopist, and the attendance or not of an anesthesiologist at the colonoscopy ( $\triangleright$ Table 3 ).

\begin{tabular}{|c|c|c|c|c|}
\hline & Bleeding & No bleeding & SD & Rate per 1000 \\
\hline$\geq 1$ colonoscopic polypectomy $=51,310$ & 219 & 51,091 & & 4.3 \\
\hline \multicolumn{5}{|l|}{ Year of false-positive gFOBT } \\
\hline - 2008-2012 & $85(38.8 \%)$ & $19,268(37.7 \%)$ & 0.02 & 4.4 \\
\hline . 2013-2017 & $134(61.2 \%)$ & $31,823(62.3 \%)$ & 0.02 & 4.2 \\
\hline \multicolumn{5}{|l|}{ Age on date of false-positive gFOBT } \\
\hline - $50-64$ & $117(53.4 \%)$ & $32,462(63.5 \%)$ & 0.21 & 3.6 \\
\hline - $65-69$ & $51(23.3 \%)$ & $10,423(20.4 \%)$ & 0.07 & 4.9 \\
\hline . $70-74$ & $51(23.3 \%)$ & $8,206(16.1 \%)$ & 0.18 & 6.2 \\
\hline \multicolumn{5}{|l|}{ Sex } \\
\hline - Female & $60(27.4 \%)$ & $19,290(37.8 \%)$ & 0.22 & 3.1 \\
\hline - Male & $159(72.6 \%)$ & $31,801(62.2 \%)$ & 0.22 & 5.0 \\
\hline \multicolumn{5}{|l|}{ Socioeconomic status } \\
\hline - Rural or missing & $36(16.4 \%)$ & $6,270(12.3 \%)$ & 0.12 & 5.7 \\
\hline - Urban median household income quintiles 1 - 3 & $109(49.8 \%)$ & $27,848(54.5 \%)$ & 0.09 & 3.9 \\
\hline
\end{tabular}


- Table 3 (Continuation)

\begin{tabular}{|c|c|c|c|c|}
\hline & Bleeding & No bleeding & SD & Rate per 1000 \\
\hline - Urban median household income quintiles 4 - 5 & $74(33.8 \%)$ & $16,973(33.2 \%)$ & 0.01 & 4.4 \\
\hline \multicolumn{5}{|l|}{ ACG Resource Utilization Band } \\
\hline . $0-3$ & $138(63.0 \%)$ & $38,835(76.0 \%)$ & 0.29 & 3.5 \\
\hline . 4-5 & $81(37.0 \%)$ & $12,256(24.0 \%)$ & 0.29 & 6.6 \\
\hline \multicolumn{5}{|l|}{ Deyo modification of Charlson score } \\
\hline .0 & $161(73.5 \%)$ & $43,585(85.3 \%)$ & 0.29 & 3.7 \\
\hline - $\geq 1$ & $58(26.5 \%)$ & $7,506(14.7 \%)$ & 0.29 & 7.7 \\
\hline \multicolumn{5}{|l|}{ Diabetes mellitus } \\
\hline - Yes & $67(30.6 \%)$ & $12,772(25.0 \%)$ & 0.13 & 5.2 \\
\hline - No & $152(69.4 \%)$ & $38,319(75.0 \%)$ & 0.13 & 4.0 \\
\hline \multicolumn{5}{|l|}{ Chronic obstructive pulmonary disease } \\
\hline - Yes & $41(18.7 \%)$ & $8,401(16.4 \%)$ & 0.06 & 4.9 \\
\hline - No & $178(81.3 \%)$ & $42,690(83.6 \%)$ & 0.06 & 4.2 \\
\hline \multicolumn{5}{|l|}{ Ischemic heart disease hospitalization } \\
\hline - Yes & $18(8.2 \%)$ & $1,724(3.4 \%)$ & 0.21 & 10.3 \\
\hline - No & $201(91.8 \%)$ & $49,367(96.6 \%)$ & 0.21 & 4.1 \\
\hline \multicolumn{5}{|l|}{ Number of patients categorized by endoscopist's specialty } \\
\hline - Gastroenterology & $75(34.2 \%)$ & $16,768(32.8 \%)$ & 0.03 & 4.5 \\
\hline - General Surgery & $117(53.4 \%)$ & $27,570(54.0 \%)$ & 0.01 & 4.2 \\
\hline - Internal Medicine or other & $12(12.3 \%)$ & $6,753(13.2 \%)$ & 0.03 & 1.8 \\
\hline \multicolumn{5}{|c|}{ Number of patients categorized by endoscopist's prior year colonoscopy volume } \\
\hline - $0-202$ colonoscopies (lowest quartile of prior year volume) & $9(4.1 \%)$ & $1,772(3.5 \%)$ & 0.03 & 5.1 \\
\hline - 203-680 colonoscopies (interquartile range) & $113(51.6 \%)$ & $21,413(41.9 \%)$ & 0.2 & 5.2 \\
\hline - $\geq 681$ colonoscopies (highest quartile of prior year volume) & $97(44.3 \%)$ & $27,906(54.6 \%)$ & 0.21 & 3.2 \\
\hline \multicolumn{5}{|l|}{ Complexity of colonoscopic polypectomy } \\
\hline - Complex polypectomy & $27(12.3 \%)$ & $1,906(3.7 \%)$ & 0.32 & 14.2 \\
\hline - Standard polypectomy & $192(87.7 \%)$ & $49,185(96.3 \%)$ & 0.32 & 3.9 \\
\hline \multicolumn{5}{|l|}{ Anesthesia attendance } \\
\hline - Yes & $108(49.3 \%)$ & $26,514(51.9 \%)$ & 0.05 & 4.1 \\
\hline - No & $111(50.7 \%)$ & $24,577(48.1 \%)$ & 0.05 & 4.5 \\
\hline
\end{tabular}

Among the 51,310/121,626 (42.2\%) of patients who underwent polypectomy, the rate of admission to hospital for bleeding $\leq 14$ days following colonoscopic polypectomy was 4.3 per 1,000 . The rate of post-polypectomy bleeding was higher among those at age 70 to 74 years $(6.2$ per 1,000$)$, among males (5.0 per 1,000), Resource Utilization Bands 4 and 5 (6.6 per 1,000), 5-year cumulative Charlson score (7.7 per 1,000), diabetes mellitus (5.2 per 1,000, prior hospitalization for ischemic heart disease $(10.3$ per 1,000$)$, and rural residence $(5.7$ per 1,000$)$. There was no difference in the rate per 1,000 between the earlier and later periods or with the presence or absence of chronic obstructive lung disease.

The rate of admission for post-polypectomy bleeding did not appear to vary by clinical specialty of the endoscopist, but was lower for those patients for whom the prior year colonoscopy volume of their endoscopist was in the highest quartile $(3.2$ per 1,000). Among those who underwent complex polypectomy, the rate of admission for bleeding was 14.2 per 1,000 . 
Bleeding rates did not appear to differ if anesthesia was in attendance at colonoscopy or not.

\section{Discussion}

We have estimated the rate of hospitalization for perforation following colonoscopy for a population-based CRC screening program positive gFOBT at 0.6 per 1,000 from 2008 to 2012 and 0.4 per 1,000 from 2013 to 2017 , and the rate of hospitalization for post-polypectomy bleeding at 4.3 per 1,000 without meaningful change between the two periods. We have stratified the rates by major patient baseline covariates, and using standardized differences, have demonstrated the importance of elevated rates among several strata. Among colonoscopies performed by endoscopists in the three lower quartiles of prior year colonoscopy volumes, the rates of perforation and postpolypectomy bleeding are elevated. These stratified rates have not been reported previously for stool testing-based population wide colorectal screening programs. This information may help guide enhancement of colonoscopy quality improvement processes.

Our overall rates of perforation and post-polypectomy bleeding results replicate the findings of the English Large Bowel Screening Program from 2006 to 2014 in the case of perforation [12], and during the period 2010 to 2014, in the case of post-polypectomy bleeding [13], despite the major differences in methods between this present study and those reports. The English Bowel Cancer Screening Programme reported colonic perforation among 147 individuals/263,129 who underwent colonoscopy following positive gFOBT between 2006 and 2014, including individuals for whom a CRC was diagnosed during the procedure [12].This program also reported post-polypectomy bleeding among 68/11,564 (0.59\%) gFOBT positives in one region of England between 2010 and 2014 [13], who underwent polypectomy during 15,285 colonoscopies ( 1.3 colonoscopies per person, post polypectomy bleeding per colonoscopy $0.44 \%$ ). Among the regional population-based screening programs using stool testing (mainly the fecal immunochemical test) in Italy, from 2011 to 2012, perforation at colonoscopy for positive screenees was reported for $0.09 \%$ those undergoing polypectomy and $0.02 \%$ of those without polypectomy [14]. During the same period, these programs reported postpolypectomy bleeding among $0.29 \%$ and among $0.06 \%$ of those without polypectomy.

Meta-analyses of publications confined to [14], or including, bleeding and perforation among colorectal screenees [15], have produced divergent results, which also diverge from the findings in this paper, which are consistent with those of the English Bowel Cancer Screening Programme. Reumkens et al [16] reported the perforation rate among screening and surveillance studies to be 0.3 per 1,000 (95\% confidence interval (Cl) $0.2,0.5$ per 1,000$)$, compared to 1.3 per $1,000(95 \% \mathrm{Cl}$ $0.6,2.3$ ) among symptomatic patients, and the bleeding rate to be 2.4 per $1,000(95 \% \mathrm{Cl} 0.9,4.6$ per 1,000$)$, compared to 4.6 per 1,000 (95\% Cl $0.1,15.8$ per 1,000$)$ among symptomatic patients. Vermeer et al [15] reported rates confined to studies of screen-related morbidity, finding perforation at 0.07 per
$1,000(95 \% \mathrm{Cl} 0.006,0.17$ per 1,000$)$ and bleeding at 0.8 per $1,000(95 \% \mathrm{Cl} 0.18,1.63$ per 1,000$)$.

Several recent publications have presented complications of colonoscopy among millions of patients with records in population-wide administrative databases. Among 1,580,000 patients undergoing screening or surveillance colonoscopy between 2005 and 2011, Wang et al [17] report rates of perforation 5.3 (95\% Cl 4.8 to 5.9 ) per 10,000 without polypectomy and 6.3 (95\% Cl 5.8 to 6.8 ) per 10,000 , comparable to our estimates. The rate of post-polypectomy bleeding is 36.4 per 10,000 (95\% Cl 25.1 to 3.76), slightly lower than our estimates. Our group has estimated 0.46 perforations per 1,000 colonoscopies among 3,059,045 individuals between 2005 and 2012, not stratified by indication [18]. Laanani et al [19] presented rates of perforation and bleeding among 4,088,799 patients with records for colonoscopy for which indication is unknown, between 2010 and 2015 in a national database in France, describing perforation rates between 3.5 to 7.3 per 10,000 and bleeding rates between 6.5 and 23.1 per 10,000 . Rates stratified by endoscopist characteristics are not presented, however, the adjusted odds ratio for perforation was significantly elevated among endoscopists with prior year colonoscopy volume $\leq 299$ procedures.

Our prior work $[8,18]$ and the work of Laanani [19] have demonstrated an association of lower endoscopist colonoscopy volume and higher rates of complication among colonoscopies for multiple indications. A recent meta-analysis of the potential association between endoscopist volume and colonoscopy quality by Forbes [20] demonstrated a non-significant trend of lower rates of adverse events overall with increasing annual volume. Some population-based colorectal screening programs have instituted overall monitoring of colonoscopy quality [2123] audit and feedback to endoscopists [24] in addition to educational interventions for endoscopists [25] with some evidence of modest improvement in performance on measures of outcomes observed relatively frequently in our own work under review. Given the low frequency of perforation and bleeding, most endoscopists would have no such events, or at most, very few events annually. Accordingly, it is only feasible to monitor these events and their secular trends on a programwide and/or institutional basis rather than at the level of the individual endoscopist, and it will be very difficult to infer a direct relationship between quality assurance, audit and feedback, and educational interventions and reduction in perforation or bleeding. That being said, there may be value for individual endoscopists to review their individual cases of perforation as there may be opportunities to learn and/or change practice going forward.

There are strengths and limitations associated with the use of the hospital database for identification of perforation and bleeding. In every hospital in Ontario, highly skilled health records technologists code diagnoses and procedures, using province-wide standardized coding rules, based on the International Classification of Diseases, version 10, and the Canadian Classification of Interventions. The assigned codes are uploaded into a uniform data platform, the Discharge Abstract Database. The limitations derive directly from the International Clas- 
sification of Diseases, version 10, which does not contain a unique code for the exclusive identification of colonoscopic perforation or a unique code for the exclusive identification of bleeding following colonoscopic polypectomy. Furthermore, there may be multiple active diagnoses and interventions during any admission within 7 to 14 days following colonoscopy, in addition to the diagnosis and interventions related to colonoscopic perforation or bleeding following colonoscopic polypectomy.

Future work should: (1) identify more precisely participants with comorbidity most likely to have perforation or post-polypectomy bleeding from original records; (2) assess whether any of these participants have a such a high level of comorbidity that surgical treatment of colorectal cancer would be contraindicated, and who should not be screened at all; (3) determine the causal pathway between low endoscopist colonoscopy volume and increased rates of perforation and post-polypectomy bleeding; (4) determine whether any of the elements of the pathway are malleable to quality improvement; and (5) implement action on the malleable elements of the pathway, if any.

\section{Conclusions}

We have identified baseline participant and endoscopist covariates associated with elevated rates of perforation and post-polypectomy bleeding. The participant covariates pertaining to comorbidity should be studied in greater depth from original charts or with prospectively collected data. The impact of endoscopist colonoscopy volume should lead to refinement and intensification of colonoscopy improvement efforts.

\section{Acknowledgements}

This study was supported by ICES, which is funded by an annual grant from the Ontario Ministry of Health and Long-Term Care (MOHLTC). The opinions, results, and conclusions reported in this paper are those of the authors and are independent from the funding sources. No endorsement by ICES or the Ontario MOHLTC is intended or should be inferred. Datasets were linked using unique encoded identifiers and analyzed at ICES from the Ministry of Health and Long Term Care of Ontario (RPDB and OHIP), and Cancer Care Ontario (OCR). The opinions, results, views, and conclusions reported in this paper are those of the authors and do not necessarily reflect those of the ICES, the Ministry of Health and Long Term Care of Ontario, or Cancer Care Ontario, and no endorsement by these bodies is intended or should be inferred.

This work was funded by Cancer Care Ontario. The funder had no role in the design of the study or collection, analysis and interpretation of the data or in writing the manuscript.

\section{Competing interests}

At the time of data analysis, Drs. Sutradhar, Rabeneck, and Tinmouth were employees of Cancer Care Ontario, which operates ColonCancerCheck. Dr. Paszat received an operating grant from Cancer Care Ontario to conduct this work.

\section{References}

[1] Towler B, Irwig L, Glasziou P et al. A systematic review of the effects of screening for colorectal cancer using the faecal occult blood test, hemoccult. BMJ 1998; 317: 559-565

[2] Canadian Task Force on Preventive Health Care. Colorectal cancer screening: Recommendation statement from the Canadian Task Force on Preventive Health Care. CMAJ 2001; 165: 206-208

[3] Public Health Agency of Canada Recommendations for populationbased colorectal cancer screening: National Committee on Colorectal Cancer Screening. Public Health Agency of Canada; 2002: Available at (accessed July 18, 2019): https://www.canada.ca/en/publichealth/services/reports-publications/technical-report-national-committee-colorectal-cancer-screening/national-committee-colorectalcancer-screening.html

[4] Rabeneck L, Tinmouth JM, Paszat LF et al. Ontario's ColonCancerCheck: results from canada's first province-wide colorectal cancer screening program. Cancer Epidemiol Biomarkers Prev 2014; 23 : 508-515

[5] Paszat L, Sutradhar R, Tinmouth ] et al. Interval colorectal cancers following guaiac fecal occult blood testing in the Ontario ColonCancerCheck Program. Can J Gastroenterol Hepatol 2016; 2016: 4768728

[6] Deyo RA, Cherkin DC, Ciol MA. Adapting a clinical comorbidity index for use with ICD-9-CM administrative databases. J Clin Epidemiol 1992; 45: 613-619

[7] Johns Hopkins ACG System. (accessed June 16, 2020): www.hopkins acg.org/

[8] Rabeneck L, Paszat LF, Hilsden R] et al. Bleeding and perforation after outpatient colonoscopy and their risk factors in usual clinical practice. Gastroenterology 2008; 135: 1899-1906, 1906.e1

[9] Rabeneck L, Saskin R, Paszat LF. Onset and clinical course of bleeding and perforation after outpatient colonoscopy: a population-based study. Gastrointest Endosc 2011; 73: 520-523

[10] Stuart EA, Lee BK, Leacy FP. Prognostic score-based balance measures can be a useful diagnostic for propensity score methods in comparative effectiveness research. J Clin Epidemiol 2013; 66: S84-\$90

[11] Austin PC. Using the standardized difference to compare the prevalence of a binary variable between two groups in observational research. Commun Statistics Sim Comput 2009; 38: 1228-1234

[12] Derbyshire E, Hungin P, Nickerson C et al. Colonoscopic perforations in the English National Health Service Bowel Cancer Screening Programme. Endoscopy 2018; 50: 861-870

[13] Derbyshire E, Hungin P, Nickerson C et al. Post-polypectomy bleeding in the English National Health Service Bowel Cancer Screening Programme. Endoscopy 2017; 49: 899-908

[14] Zorzi M, Mangone L, Sassatelli R et al. Screening for colorectal cancer in Italy: 2011-2012 survey. Epidemiol Prev 2015; 39: 115-125

[15] Vermeer NC, Snijders HS, Holman FA et al. Colorectal cancer screening: Systematic review of screen-related morbidity and mortality. Cancer Treat Rev 2017; 54: 87-98

[16] Reumkens A, Rondagh EJ, Bakker CM et al. Post-colonoscopy complications: a systematic review, time trends, and meta-analysis of population-based studies. Am J Gastroenterol 2016; 111: 1092-1101

[17] Wang L, Mannalithara A, Singh G et al. low rates of gastrointestinal and non-gastrointestinal complications for screening or surveillance colonoscopies in a population-based study. Gastroenterology 2018; 154: 540-555.e8

[18] Bielawska B, Hookey LC, Sutradhar R et al. anesthesia assistance in outpatient colonoscopy and risk of aspiration pneumonia, bowel perforation, and splenic injury. Gastroenterology 2018; 154: 77-85.e3 
[19] Laanani M, Coste J, Blotière PO et al. Patient, procedure, and endoscopist risk factors for perforation, bleeding, and splenic injury after colonoscopies. Clin Gastroenterol Hepatol 2019; 17: 719-727.e13

[20] Forbes N, Boyne D], Mazurek MS et al. Association Between endoscopist annual procedure volume and colonoscopy quality: systematic review and meta-analysis. Clin Gastroenterol Hepatol 2020; 18: 2192-2208

[21] Tinmouth J, Kennedy EB, Baron D et al. Colonoscopy quality assurance in Ontario: Systematic review and clinical practice guideline. Can J Gastroenterol Hepatol 2014; 28: 251-274

[22] Wieten E, Spaander MC, Kuipers EJ. Accrediting for screening-related colonoscopy services: What is required of the endoscopist and of the endoscopy service? Best Pract Res Clin Gastroenterol 2016; 30: 487495
[23] Bronzwaer MES, Depla ACTM, van Lelyveld N et al. Quality assurance of colonoscopy within the Dutch national colorectal cancer screening program. Gastrointest Endosc 2019; 89: 1-13

[24] Tinmouth J, Patel J, Hilsden RJ et al. Audit and feedback interventions to improve endoscopist performance: Principles and effectiveness. Best Pract Res Clin Gastroenterol 2016; 30: 473-485

[25] Bishay K, Causada-Calo N, Scaffidi MA et al. Associations between endoscopist feedback and improvements in colonoscopy quality indicators: a systematic review and meta-analysis. Gastrointest Endosc 2020: doi:10.1016/j.gie.2020.03.3865 